\title{
LIFE CYCLE OF CEDAR PROCESSIONARY MOTH (THAUMETOPOEA ISPARTAENSIS DOĞANLAR \& AVCI) IN TURKEY (LEPIDOPTERA: NOTODONTIDAE)
}

\author{
KÜÇÜKOSMANOĞLU, A. \\ Faculty of Forestry, Istanbul University-Cerrahpaşa, Sartyer, Istanbul, Turkey \\ (e-mail:aliko@istanbul.edu.tr) \\ (Received 20 $0^{\text {th }}$ Mar 2019; accepted 24 $4^{\text {th }}$ May 2019)
}

\begin{abstract}
Thaumetopoea ispartaensis Doğanlar and Avc1 (Lepidoptera: Notodontidae) (cedar processionary moth: CPM) is one of the most dangerous pests of Cedrus libani A. Rich. living in abundance in forests of the Isparta region and some forests of Taurus Mountain in Southern Turkey. The present study was conducted to study the biology of $T$. ispartaensis which was recorded and defined first time in Turkey and its damage on cedar needles. The study was conducted in Isparta-Senirkent Kapıdağ Forests (between 1250 and $1650 \mathrm{~m} ; 38^{\circ} 06^{\prime} \mathrm{N}, 30^{\circ} 45^{\prime} \mathrm{E}$ ) where the pest caused most damage. It was determined that $T$. ispartaensis was a monophagous species of $C$. libani. The flight period of the pest lasted from mid-August to mid-September. Females laid eggs underside of twigs (mean $3.5 \mathrm{~mm}$ diameter) on the lower part of trees. Eggs were covered by scales which were colored similar to the bark of shoot. Egg numbers of egg batches varied between 39 and 245 (mean 121). The caterpillars started to hatch in the second half of April, and it had five instars. The caterpillar hatching rate from eggs was found as 87.5\%. The caterpillars which built the nests on stems and shoots fed at nights and stayed in their nests in the daytime. Mature larvae started to pass into the soil for pupating from the beginning of July. The pupation was determined in the first half of July, in a depth of 5-15 cm of soil, in the sun-exposed places in cedar woods along the sides of the roads. T. ispartaensis was determined as univoltine species.
\end{abstract}

Keywords: cedar pest, needle, moth, biology, Turkey

\section{Introduction}

Taurus cedar (Cedrus libani A. Rich.) is one of four cedar species distributed across the world. The Taurus cedar, which is naturally found in Turkey, Lebanon, and Syria, is distributed across approximately 482.391 hectares (ha) in Turkey. The broadest natural distribution of Taurus cedar, one of the most important forest trees of Turkey, is in the Taurus Mountains of Turkey. Cedar is significant from the historical, cultural, aesthetic, scientific and economic perspectives (Aksoy and Özalp, 1990; Anonymous, 2015). It grows in Mediterranean Mountain climates and has distinct ring boundaries. Its growth age is said to reach up to 500 years. Cedar generally occurs between 800 and $2100 \mathrm{~m}$ elevations (Evcimen, 1963).

The species of the genus Thaumetopoea (Lepidoptera, Notodontidae, Thaumetopoeinae) has an important place in forest fauna and human health as they are defoliators of trees and they release urticating hairs at the larval stage that are a source of allergy. Within the genus, there are two groups associated with conifers which are characterized by larval feeding in winter or spring-summer, so the groups are called 'winter' and 'summer' processionary moths (Basso et al., 2016).

Three species of processionary moths (Notodontidae: Thaumetopoeinae) can be found in cedar (Cedrus spp.) including Thaumetopoea bonjeani (Powell) in C. atlantica Man. in North Africa (Tunisia, Morocco, and Algeria), T. libanotica Kiriakoff \& Talhouk in Lebanon and T. ispartaensis in C. libani in Turkey (Battisti et al., 2015). These species are close to T. pinivora living on pines in Europe and belong to the group 
of the "summer processionary caterpillars." All have their larval development from the beginning of spring until the beginning of summer (Demolin, 1988; El Yousfi, 1989; Kiriakoff and Talhouk, 1975; Mouna and Fabre, 2005).

T. ispartaensis has been identified as a new species from Turkey in the Isparta region of Asia Minor located in the Lakes District area in 2001. T. ispartaensis is one of the most important insects of Taurus cedar forests in the Isparta region and in some forests of Taurus Mountain in Southern Turkey. The only determined host species of $T$. ispartaensis is $C$. libani. The wingspan of the males and females is $26-29 \mathrm{~mm}$ and 34$37 \mathrm{~mm}$, respectively. The larvae feed on the needless of cedar trees and produce tiny hairs containing and urticating substance, which causes contact dermatitis (Doğanlar and Avc1, 2001).

\section{Materials and methods}

The studies of the biology of the insect were carried out at Isparta/Senirkent Kapıdag cedar forest where the insect was first detected. Field studies were conducted between 2012 and 2016 to determine the biology of the pest in natural conditions. Most of the egg clusters and larvae various stages were collected in the forest during study period. Eggs collected from the field were brought to the laboratory and measurements and counts were performed.

The study area was located in the Western Mediterranean of Turkey. It was about $65 \mathrm{~km}$ from Isparta city (Fig. 1). The study area is located at $38^{\circ} 06^{\prime} \mathrm{N}$., $30^{\circ} 45^{\prime} \mathrm{E}$., average slope $23^{\circ}$, predominately north facing aspect, about $1365 \mathrm{~m}$ altitudes, and about 1223 ha in size. The study area is found on calcareous formations of Eocene age. The soil varies from shallow to medium and medium-deep and is generally stony. The soil is varies from shallow, medium, medium-deep, and are generally stony. However, many cracks between limestone blocks contain fine soil and create a physiologically deep soil (Evcimen, 1963). This region is in the transitional zone between the Mediterranean climate and the continental climate with colder winters and hotter summers.

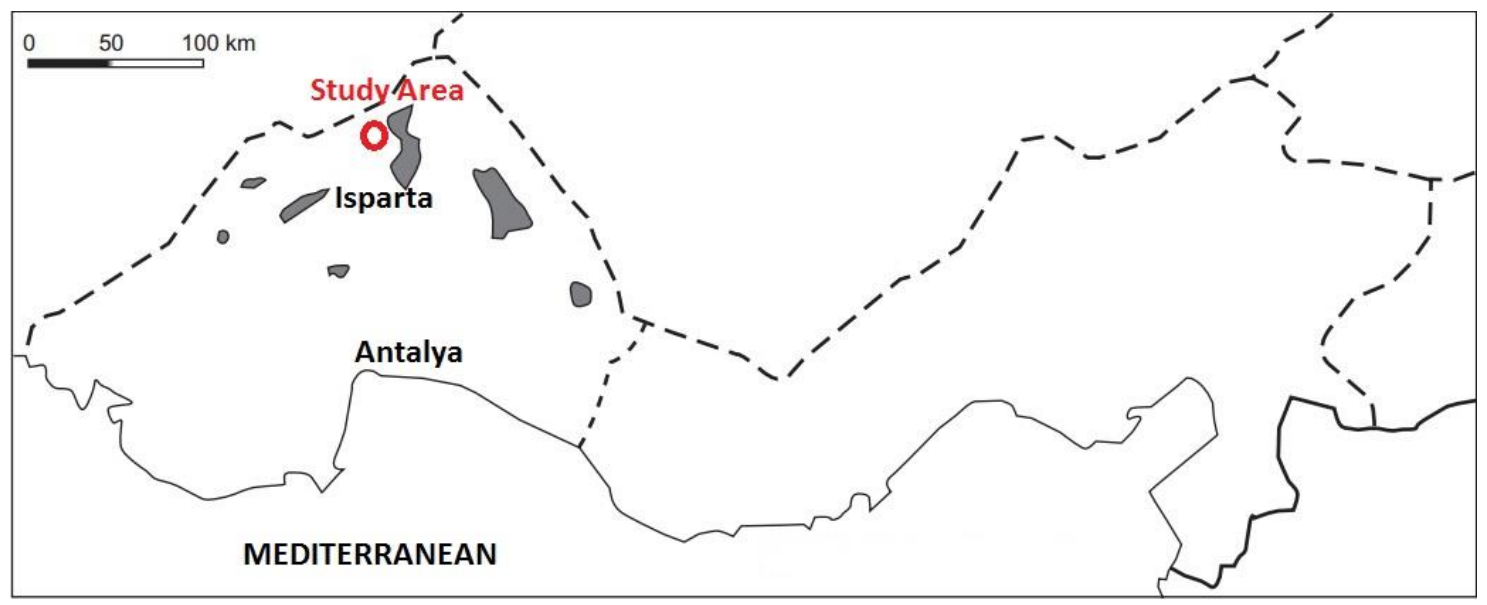

Figure 1. The study area in Isparta City, south-western Anatolia, Turkey

The egg-batches were collected in October-December 2013 and 2014. All eggbatches were taken from underside of twigs of $C$. libani. Ninety-five egg-batches, 
oviposited over two annual generations, were studied. After collection, the batches were put singly in test tubes with cotton stoppers and placed in the laboratory at $21-24{ }^{\circ} \mathrm{C}$, where further investigations were also performed. The scales covering the egg-batches were removed, counted and measured.

The biology of the pest has been tracked in field conditions. For this purpose, observations were made with periods of 2-3 weeks within the fields, in areas where the spread of the insect was determined. In the egg period, following the hatched of larvae up to pupa period studies were carried out within certain trees. In order to determine some morphological features of T. ispartaensis, several measurements and observations were made in larvae and pupae collected from field. Measurements were performed on 20 individuals for each period. Field observations were recorded on a regular basis and the biology of the insect in natural conditions was determined. Also, mature larvae and pupae brought to the laboratory were monitored until the adult outgrowth, within the plastic containers that have soil in their lower part.

\section{Results}

Thaumetopoea ispartaensis (described as Traumatocampa ispartaensis by Doğanlar and Avc1 in 2001) is one of the most dangerous pests living in the Cedrus libani forests in the Isparta region and on the Taurus Mountains in Southern Turkey. The pest is distributed between 1250 and $1650 \mathrm{~m}$. The caterpillars feed on the needles of cedar trees and have urticating hairs that cause contact dermatitis especially after the third instar.

The study was conducted in Isparta/Senirkent Kapıdağ Cedar Forest where the most massive damage occurred. It was determined that $T$. ispartaensis is a monophagous species and feed on only $C$. libani. $T$. ispartaensis belongs to the group of the summer processionary moths, just like $T$. pinivora, and adapts to high elevation.

Adults appear from the mid-August to the end of September, depending on the temperature and altitude (earlier at a lower elevation). Egg-laying started soon after emergence and copulation, as in other Notodontidae species. Copulation started a few hours after the adults had emerged and then egg deposition took place during the same night. Females oviposit on the underside of $C$. libani twigs. Egg batches are covered by grayish brown scales, similar to the color of the bark, and therefore the batches are indistinguishable. Only one egg-batch was laid by one female during its very short life. Oviposition by the moth in all cases was found to occur from the tip to base of the twigs. This observation was made based on the position of scales which covered the eggs. The eggs were deposited below the surface of the twigs were 2-5 mm diameter (average $3.5 \mathrm{~mm}$ ). The color of the eggs was white. The length of the egg-batches varied from 7 to $36 \mathrm{~mm}$ (average $17 \mathrm{~mm}$ ). A one $\mathrm{cm}$ egg-row contained a mean number of 10.5 (10.1-10.9) eggs (Fig. 2).

The number of eggs per egg batch varies between 39 and 245 (mean 121). The eggs hibernate and this period continues for approximately seven months. The larvae hatched in the last week of March and the first half of April of the following year and started to cause damage by feeding needles. It was observed that the larvae fed in nights and stayed in nests during day time.

The larvae live together in silky grayish nests until the $5^{\text {th }}$ instar which is the last instar. They build their loose nests on the trunk or branch of host trees and nests become thicker (but it is still quite loose in comparison to pine processionary moth nests) as larvae feed during 2.5 months, generally between the late April and mid-July. In spring, 
larvae resume feeding on the needles, reaching up to $3.0-3.5 \mathrm{~cm}$ in length by summer. The mature larvae are the most destructive ones and may cause severe infestation resulting in the complete defoliation of large surfaces of cedar forests. The nests become clear in May and grow large at the end of this month. They spin cotton like webs when they are active. The mature larvae of $T$. ispartaensis live in aggregations in silky nests (Fig. 2). Damaged parts of the tree with dead agglutinated needles remain long after the feeding period.
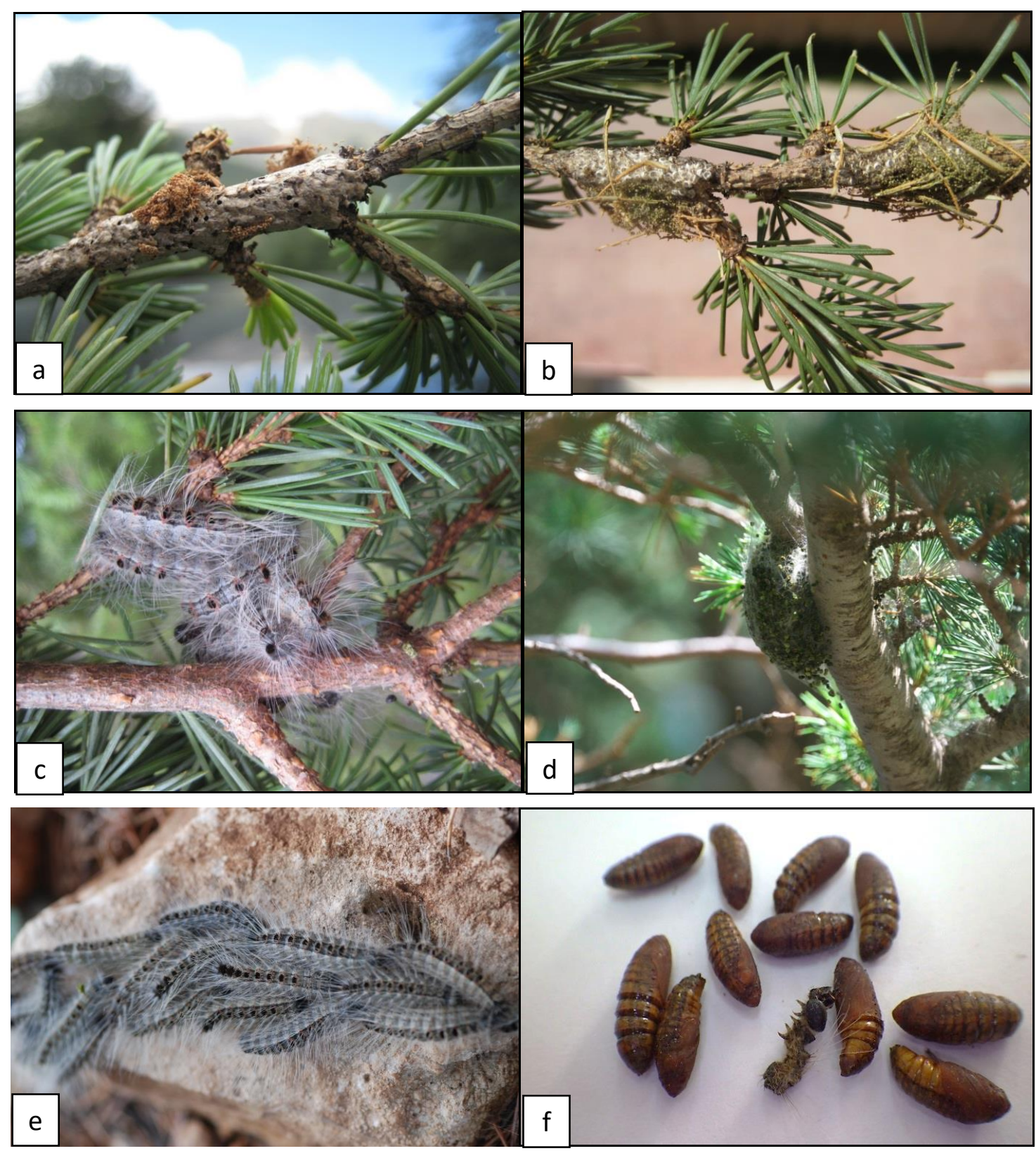

Figure 2. Thaumetopoea ispartaensis a) egg batches b) damage that young larvae cause c) mature larvae d) nest of larvae e) larvae on soil for pupation f) pupae

The pupation takes places at the beginning of July in lower elevations, and it takes places in the second half of this month in higher altitudes, in a depth of 5-15 cm of soil, 
in sunlit cedar forest floors, especially along roadsides. In mid-June, fully grown larvae of $T$. ispartaensis drop to the forest floor and pupate in the surface litter and soil. There follows a short pre-pupal stage, after which the pupae remain in the litter until adult emergence. The pupa develops in a cocoon which is gray-brown (Fig. 2). There is no observation about the capacity of the pupae to prolong the diapause.

The adult appears in the middle of August, and adult hatchings become the highest level in the last period of this month. Flying period continues in September decreasingly. It was determined that $T$. ispartaensis has one generation and the mean lengths of egg, larva, and pupa periods are 228, 98 and 36 days, respectively (Fig. 3).

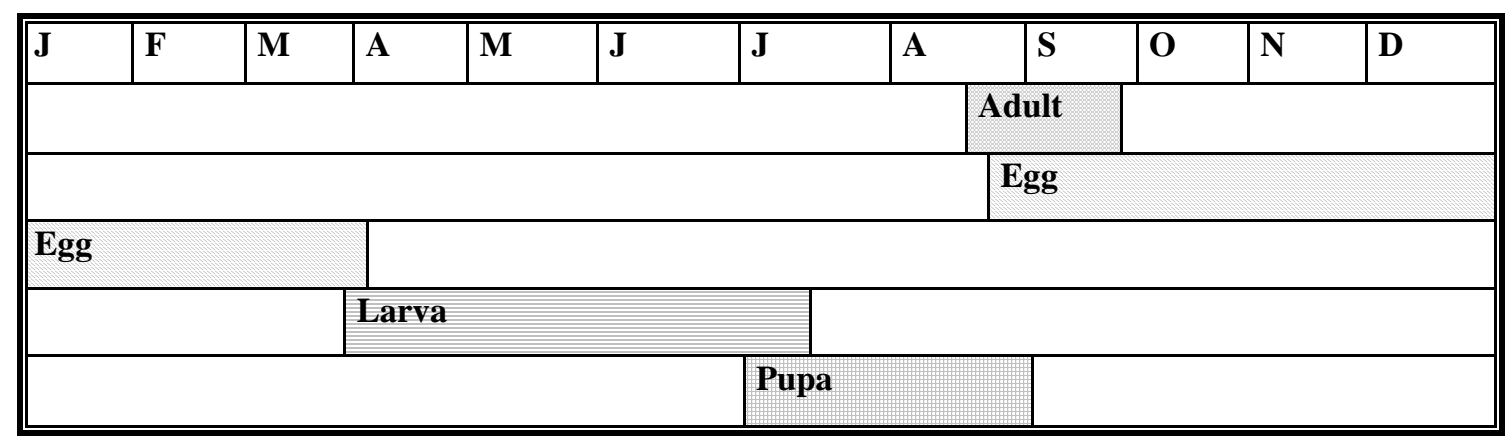

Figure 3. Life history of Traumatocampa ispartaensis Doğanlar \& Avcl in Turkey

\section{Discussion}

T. ispartaensis display similar phenology as T. bonjeani in the C. atlantica forest in the Atlas Mt. in North Africa. Oviposition of T. bonjeani takes place in August-September on small twigs, and the eggs are also covered with scales. The eggs hibernate and hatch in the spring during March-April of the following year (Demolin, 1988).

At the same time, the biology of $T$. ispartaensis, shows great resemblance with the biology of T. libanotica that located in the forests of Bsharry, Tannourine and Shouf in Lebanon. T. libanotica lives in these regions between 1400-2000 m above sea level and its adult period is remarked as August-October (Kiriakoff and Talhouk, 1975; Nemer et al., 2018).

The egg rows of $T$. ispartaensis were not generally tidy, more random than the egg rows of $T$. pityocampa, $T$. wilkinsoni or $T$. solitaria. The eggs of $T$. solitaria are white above, grayish-yellow below, hexagonal and deposited in a flat, one layered, symmetrical, hexagonal cluster. The eggs of T. pityocampa and T. wilkinsoni are deposited around one or more pine needles or small twigs. They are deposited in one-layered cylindrical clusters. $\mathrm{T} r$. ispartaensis eggs were observed to be white in contrast to the eggs of T. pityocampa.

Cedar processionary moth significantly damages Cedrus libani. In the spring of 1998, a notodontid moth, an outbreak of the cedar processionary moth $T$. ispartaensis, began about 400 ha in 75-year-old Lebanon cedar trees in Isparta. From 1999 to 2003, CPM larvae were present in the same stands and again caused defoliation. We identified regional outbreaks of CPM by synchronous and sustained growth periods of the trees. Growth functions were defined as the cumulative sum of radial increment. Tree ring evidence suggests that a large scale outbreak occurred in 1954 (from 1954 to 1961) and small outbreaks occurred in 1947 (1947-1951), in 1985 (1985-1988), and 1998 (1998-2003) in the study area. The average diameter growth reductions for around 1947, 1954, 1985, and 1998 were 40\%, 28\% 17\%, and $10 \%$ of potential, respectively. 
T. ispartaensis population in Isparta has been observed since 1999, and an outbreak was recorded only between 1998 and 2003 (Avc1 and Carus, 2005), whereas it was impossible to see even a single nest in some years such as 2012. Further studies are indeed required to understand the population dynamics of the species.

The conifers of the genus Cedrus seem to be associated with the summer Thaumetopoea, although further studies are needed to clarify the evolutionary history of the group (Basso et al., 2016).

Thaumetopoea ispartaensis belongs to the Thaumetopoea genus, of which four other species are wide spread in Turkey, namely wilkinsoni, pityocampa, solitaria and processionea attacking various types of plants and trees. A detailed study of the biology of the cedar processionary moth in the all stages has been presented in this study.

\section{REFERENCES}

[1] Aksoy, H., Özalp, G. (1990): Forest communities of cedar in Turkey. - Proceedings of International Cedar Symposium, 22-27 October 1990, Antalya, pp. 93-102 (in Turkish).

[2] Anonymous (2015): Turkey Forests Assets. - Republic of Turkey, Ministry of Forestry and Water Affairs, General Directorate of Forestry, Ankara, Turkey (in Turkish).

[3] Avc1, M., Carus, S. (2005): The impact of cedar processionary moth [Traumatocampa ispartaensis (Doğanlar \& Avc1) (Lepidoptera: Notodontidae)] outbreaks on radial growth of Lebanon cedar (Cedrus libani A. Rich.) trees, Turkey. - J. Pest Sci. 78: 91-98.

[4] Basso, A., Simonato, M., Cerretti, P., Paolucci, P., Battisti, A. (2016): A review of the "summer" Thaumetopoea spp. (Lepidoptera: Notodontidae, Thaumetopoeinae) associated with Cedrus and Pinus. - Turkish Journal of Forestry 17(Special Issue): 31-39.

[5] Battisti, A., Avc1, M., Avtzis, D. N., Ben Jamaa, M. L., Berardi, L., Berretima, W., Branco, M., Chakali, G. et al. (2015): Natural History of the Processionary Moths (Thaumetopoea spp.): New Insights in Relation to Climate Change. - In: Roques, A. (ed.) Processionary Moths and Climate Change: An Update, Chapter 2. Springer, Dordrecht, pp. 15-79.

[6] Demolin, G. (1988): La processionaire du cedre: Thaumetopoea bonjeani (Powell), Rapport Scientifique et Rapport Iconographique-Intensification de la Protection Phytosanitaria des Forēsts, Algeria 1986-1987. - FAO-Report. FAO, Rome.

[7] Doğanlar, M., Avc1, M. (2001): A new species of Traumatocampa Wallengren (Lepidoptera: Thaumetopoeidae) feeding on cedar from Isparta (Turkey). - Tr. J. of Ent. 25(1): 19-22.

[8] El Yousfi, M. (1989): La processionaria del cedro, Thaumetopoea bonjeani (Powell). Bol. Sanidad. Veg. Plagas. 15: 43-46.

[9] Evcimen, B. S. (1963): The yield, economic important and management basis of the Lebanon cedar forests. - OGM Publ. no: 355/16. Ankara, Turkey (in Turkish with English summary).

[10] Kiriakoff, G., Talhouk, A. S. (1975): Thaumetopoea libanotica spec. nov. (Lepidoptera: Thaumetopoeidae). - Opusc. Zool. (Munich) 137: 1-5.

[11] Mouna, M., Fabre, J. P. (2005): Pests Insects of Cedars: Cedrus atlantica Manetti, $C$. libani A. Richard and C. brevifolia Henry in the Mediterranean Area. - In: Lieutier F., Ghaioule, D. (eds.) Entomological Research in Mediterranean Forest Ecosystems. INRA Editions, Paris, pp. 89-104.

[12] Nemer, N., Najem, M., Ezzedine, S., Frerot, B. (2018): Insights on the Thaumetopoea species in Lebanon and identification of Thaumetopoea libanotica sexual pheromone. First Meeting Working Group (Processionary moth), 05-08 December, Hammamet, Tunisia. 